\title{
O NÃO-LUGAR DA ANORÉXICA NUMA SOCIEDADE EM REDE E DO ESPETÁCULO
}

\author{
Mariele Zawierucka Bressan ${ }^{47}$
}

RESUMO: Neste trabalho, situamo-nos no terreno da Análise do Discurso (AD) de linha pecheutiana, a fim de melhor visualizarmos o corpo como materialidade significante e discursiva, como lugar de memória e, a partir de tais pressupostos, empreender um estudo sobre a anorexia nervosa, concebendo-a como um dos sintomas da sociedade do espetáculo e da sociedade em rede. Temos como arquivo o discurso de anoréxicas em blogs do gênero pró-ana, a partir do qual fazemos movimentar as noções de lugar social e de lugar discursivo, abordando, para tanto, a historicidade da anorexia nervosa e a produção de sentidos relativos ao sintoma no tempo e no espaço. De "Ana, a santa" à profanação dos espetáculos circenses, a anoréxica, na atualidade, ocupa distintos lugares sociais - o blog, o documentário, o consultório, a família - que, no espaço discursivo, tornam-se lugares discursivos, pelos quais ficamos sabendo que pode ser tanto a "porca louca" quanto a "borboleta". Diante dessa tomada de posição paradoxal do sujeito, propomos a articulação do que chamamos de não-lugar, ou lugar de entremeio, como um lugar em que se materializa tanto o processo de contra-identificação quanto a resistência.

Palavras-chave: Corpo; Anorexia nervosa; Não-lugar; Resistência.

ABSTRACT: On this study, we have allocated ourselves on the terrain of Pêcheux's Discourse Analysis (DA), in order to better visualize the body as significant and discursive materiality, as a memory place and, based on these assumptions, undertake a study on anorexia nervosa, conceiving it as one of the symptoms from the society of the spectacle and the networked society. We present, here, the speeches of anorexic women in Pro-Ana blogs as its archive. We make the notions of social and discursive places start to move, addressing, for this purpose, to historicity of the anorexia nervosa and the production of senses related to the symptom in

47 Professora de Língua Portuguesa na URI - Campus de Erechim/RS. Orientadora pedagógica da SMECD de Getúlio Vargas. Doutora em Letras pela Universidade Federal do Rio Grande do Sul. 
time and space. From "Ana, the saint" to the desecration of circus spectacles, the anorexic, nowadays, holds distinct social places - the blog, the documentary, the clinic, the family - which, in the discursive space, becomes discursive place named as either "crazy pig" or "butterfly". Given this paradoxal position taken by the subject, we have proposed the articulation of what we call the non-place, or place of in-between, as a place in which it materializes both the process of counter-identification and the resistance.

Keywords: Body; Anorexia Nervosa; Non-place; Resistance.

\section{Para iniciar a conversa}

Ao se deparar com o título deste trabalho, nosso possível leitor pode se perguntar o que faz um analista do discurso estudando o corpo o corpo doente das anoréxicas. Mais do que isso, o que tem a ver o corpo em processo de definhamento dessas moças com noções como as de lugar social, lugar discursivo e não-lugar?

Diante desses possíveis questionamentos, que só fazemos porque em nós habitam as formações imaginárias, nos colocamos na posição não daqueles que procuram respostas e, desse modo, daqueles que procuram dar respostas a esse provável leitor. Colocamo-nos na posição daqueles que, diante do óbvio, se lançam a mais perguntas.

Ora, estudar o corpo doente é coisa para a medicina, para a biologia, para os especialistas da área da saúde. A anorexia, então, como enfermidade mental, é coisa para a psiquiatria, para a psicologia. É coisa que, também, rompendo com o logicamente estabilizado pelos saberes acadêmicos, pode concernir à Análise do Discurso (AD).

$\mathrm{A} \mathrm{AD}$, ainda que recentemente, incluiu o corpo como objeto de análise. No entanto, o modo como esta disciplina de interpretação se propõe a estudar o corpo difere do modo como é estudado por outras áreas do conhecimento. Para a $\mathrm{AD}$, o corpo não se resume a uma entidade de carne e osso. Ao contrário, o corpo é visto como uma materialidade significante e discursiva pela qual se tem acesso ao discurso. Em outras palavras, o corpo produz efeitos de sentido, os quais são construídos no interior de formações sociais, culturais, ideológicas, discursivas, imaginárias, inconscientes. 
É com base nisso que, nesse trabalho ${ }^{48}$, estudamos o corpo das anoréxicas numa sociedade em rede e do espetáculo, buscando visualizar que lugares ocupa esse corpo, sobretudo o blog do gênero pró-ana. Observamos, também, a instituição do não-lugar, ou, como temos proposto, o lugar de entremeio, como uma das formas pelas quais o sujeito, ao tomar posição, se subjetiva.

\section{O corpo, numa sociedade em rede e do espetáculo}

Recentemente, na grande rede, a Internet, temos acesso a um espetáculo, materializado por anoréxicas, nos blogs conhecidos como próana. Blogs em que leitoras e autoras compartilham (ou não) sua identificação ao que a medicina chamou de anorexia nervosa.

Nesses blogs, é comum lermos enunciados que materializam um posicionamento favorável à anorexia e à bulimia. É com materialidades tais como essa que trabalhamos. É sobre o corpo de jovens que "buscam a felicidade" por meio da anorexia e expressam isso na mídia, em especial no ciberespaço, em blogs disponíveis na Internet, que lançamos nosso olhar e imprimimos nossa escuta discursiva. Não se trata, porém, de uma busca qualquer, por parte de tais jovens. Trata-se de uma busca pela felicidade que perpassa o corpo, que se dá no e pelo corpo. $O$ corpo passa a ser objeto - instrumento pelo qual a felicidade pode ser alcançada. E essa felicidade relaciona-se com um corpo emagrecido que, por um efeito metafórico, passa a ser um corpo anoréxico, um corpo cadavérico.

Falamos de um corpo que ocupa lugar no tempo e no espaço; que ocupa lugar numa determinada formação social. Por formação social entendemos a forma como a sociedade se estrutura, a partir de um determinado modo de produção. Nesse caso, falamos de um modo de produção capitalista, pelo qual se organiza a sociedade em rede e do espetáculo. Aliás, é no interior de uma formação social capitalista que podemos falar em formas de organização em rede e do espetáculo.

O corpo - o corpo das anoréxicas - ocupa lugar nessa formação social. A sociedade do espetáculo de que tratamos diz respeito ao modo como conceitua Debord (2003, p. 13). Para este autor, "toda a vida das sociedades nas quais reinam as condições modernas de produção se anuncia como uma imensa acumulação de espetáculos. Tudo o que era diretamente vivido se esvai na fumaça da representação”. O espetáculo é,

\footnotetext{
${ }^{48}$ Trata-se de um recorte de nossa tese de doutorado efetuada junto ao Programa de Pós-graduação em Letras da UFRGS.
} 
ao mesmo tempo, parte da sociedade; a própria sociedade e seu instrumento de unificação. Não se trata de um conjunto de imagens, mas da relação social entre pessoas, mediatizada por imagens. Ainda, segundo Debord (ibidem), "a especialização das imagens do mundo acaba numa imagem autonomizada, onde o mentiroso mente a si próprio. $\mathrm{O}$ espetáculo, em geral, como inversão concreta da vida, é o movimento autônomo do não-vivo".

A sociedade do espetáculo tem a ver com o que, atualmente, é chamado de sociedade em rede, tal como é articulada por Castells (1999). Isso porque, de uma sociedade em rede, a partir da integração de comunicação eletrônica, do fim da audiência de massa e do surgimento de redes interativas, emerge uma determinada forma de cultura, que o autor denominou de cultura da virtualidade real.

Por cultura da virtualidade real Castells (1999) compreende um sistema em que a própria realidade - a experiência simbólica / material das pessoas - é captada e imersa em uma composição de imagens virtuais no mundo do faz-de-conta. Neste, as aparências não apenas se encontram na tela comunicadora da experiência, mas se transformam na experiência. Trata-se de uma cultura que resulta, portanto, de uma forma de organização da sociedade que o autor chama de rede, visto que integra vários modos de comunicação em uma rede interativa, a partir da comunicação mediada pela Internet.

De nossa parte, podemos pensar que, numa sociedade em rede, o que o autor chama de cultura da virtualidade real torna-se um primeiro grande paradoxo entre o real e o virtual. $\mathrm{O}$ virtual, aquilo que existe apenas em potência ou como faculdade, estabelece uma relação contraditória com o real, tomado aqui como a realidade. $\mathrm{O}$ espaço virtual torna visível aquilo que, na verdade, é invisível. O virtual, nessa forma de organização social, vai adquirindo forma material, inclusive determinando e sendo determinado pela própria realidade, de modo que essa relação paradoxal, em última instância, nos coloca diante de um certo real, do modo como o conceitua a Psicanálise - um ponto de impossível que não cessa de não se escrever.

Numa formação social caracterizada pela lógica tanto do espetáculo quanto em rede, existir passa a significar estar na imagem, se expor ao mundo como objeto do olhar. Numa cultura da realidade virtual, o faz-de-conta vai se tornando a própria realidade. O sujeito e seu corpo, capturados nessa lógica, não mais vivem, representam, encarnam personagens os quais melhor podem ocupar os lugares socialmente 
determinados para cada espetáculo. Assim pode ser com a anoréxica: em casa, na escola, no trabalho, no consultório e, em especial, no blog, como veremos no próximo tópico.

\section{O discurso das anoréxicas: uma questão de lugar(es)}

A anorexia nervosa não é uma doença tão recente assim. Ela tem sua historicidade. Dos conventos na Idade Média, aos espetáculos circenses, nos séculos XVIII e XIX, as anoréxicas passaram, na atualidade, a ser objeto de estudo da medicina e, hoje, ocupam, além dos consultórios médicos, clínicas e hospitais (na condição de doentes), o espaço virtual - os blogs. As anoréxicas, observadas pela lente da $\mathrm{AD}$, tornam-se sujeitos do discurso, ou seja, são sujeitos porque ocupam lugar numa dada formação social.

Vale lembrar que, em $\mathrm{AD}$, o sujeito não é visto como uma entidade empírica, mas como posição projetada no discurso designando lugares determinados na estrutura de uma formação social. Para Pêcheux (1993 [1969], p. 82), o funcionamento discursivo se dá pelas formações imaginárias, as quais "[...] designam o lugar que A e B se atribuem cada um a si e ao outro, a imagem que eles fazem de seu próprio lugar e do lugar do outro".

Assim, a anoréxica ocupa determinados lugares em dadas formações sociais e culturais, os quais são determinados pelas formações imaginárias que designam o que é uma anoréxica: de santa e possuída, no modo de produção feudal, à "porca louca" e "borboleta", no modo de produção capitalista. Expressões como essas são usadas pelas próprias anoréxicas, nos blogs, para designar a si mesmas, como podemos ler nos recortes discursivos abaixo, apresentados em $(01)$ e em $(02)^{49}$ :

(01) Recorte Discursivo 1 (RD1) $)^{50}$ :

Tudo bem eu sei que sumi... mas foi por motivos justos.

Não mentira não foi por motivos justos, afinal eu fiquei todo esse tempo comendo feita uma porca louca... (Grifo nosso)

(02) Recorte Discursivo 2 (RD2) ${ }^{51}$ :

49 Os referidos recortes foram retirados de blogs que, atualmente, não se encontram mais disponíveis na grande rede. Faremos, no entanto, a referência, embora os conteúdos tenham sido removidos.

50 SUMIDA eu? magina. Diário de uma garota anoréxica, 2011. Disponível em: <http://garota-anorexica.blogspot.com.br/> Acesso em: 02 set. 2016. 
Borboleta é o principal símbolo utilizado, muitas meninas chamam-se umas às outras de borboletas carinhosamente. O símbolo é uma alusão à sua beleza, leveza, e principalmente, às fases de desenvolvimento e crescimento desta. A borboleta vai de uma larva à um lindo inseto perfeito. (Grifos nossos)

Ao retomar sentidos cristalizados tanto nos conventos quanto nos circos, as anoréxicas dos blogs nos lançam a mais um paradoxo. Materializam, ao mesmo tempo, as dimensões do sagrado e do profano; tornam-se animais, tanto porcas loucas quanto borboletas, dando forma material à contradição, uma vez que, por tal conformação imaginária, produzem efeitos de sentido tanto da bestialização quanto da ascese.

Vale lembrar que, em se tratando de formações imaginárias, as imagens que os locutores atribuem a si e ao outro são determinadas por lugares empíricos / institucionais construídos no interior de uma formação social e cultural, como podemos observar no esquema a seguir:

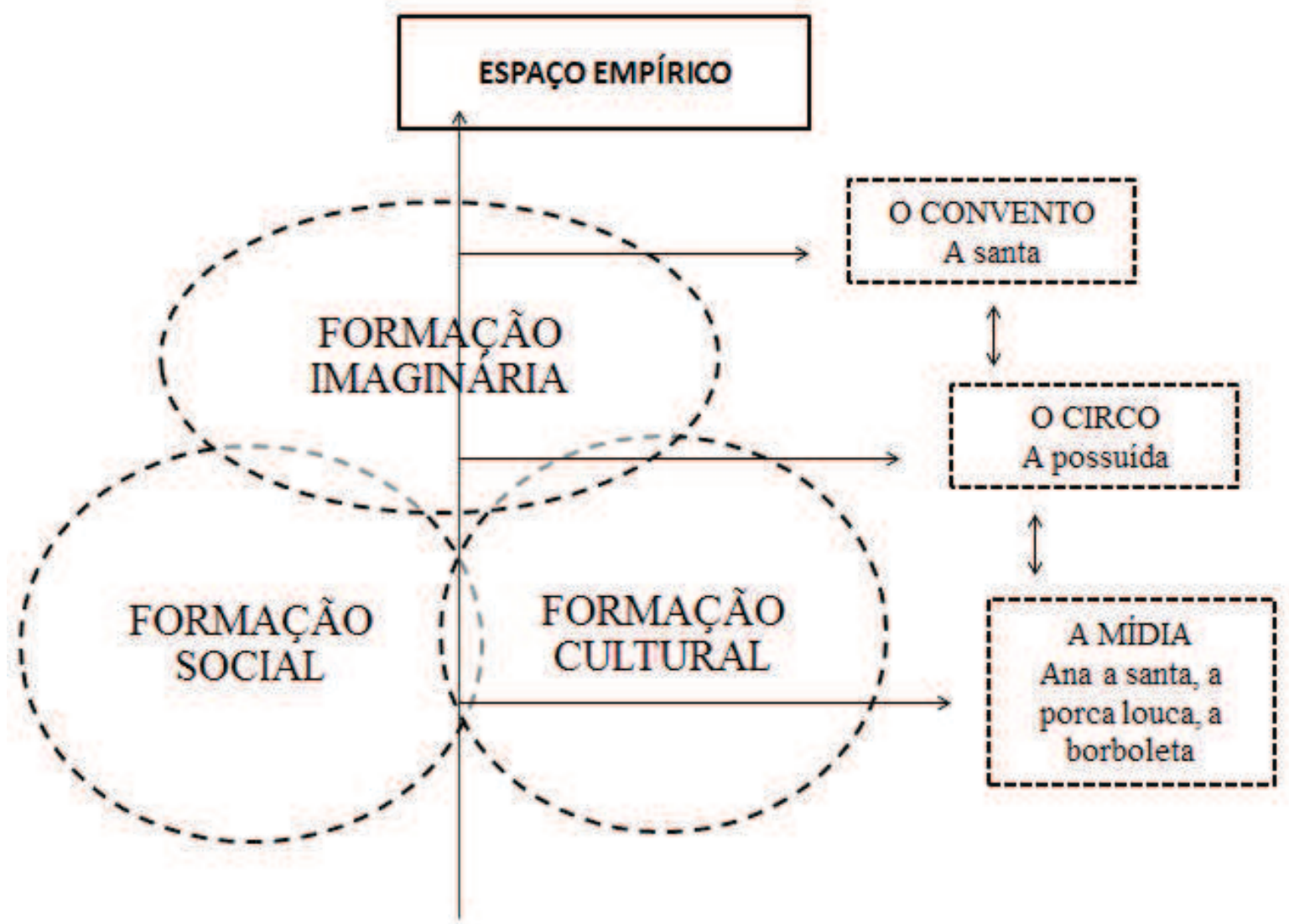

Esquema 1: Lugares sociais da anoréxica

${ }^{51}$ DONZELA, Mandy. Dicionário. Como ser uma borboleta, 2016. Disponível em: $\quad$ <http://comoserumaborboleta.blogspot.com/2016/09/adeus-ana-e-miaverdade-que-nunca-te.html> Acesso em: 02 set. 2016. 
Desse modo, a anoréxica, seja no convento, no circo, ou hoje, nos blogs, não é por nós entendida como indivíduo de carne e osso. Trata-se de posições-sujeito assumidas numa dada formação social e cultural. A formação social, segundo Grigoletto (2008, p. 58), “[...] compreende o espaço empírico e abriga diferentes formações ideológicas, as quais interagem com as relações de poder [...], determinando o lugar social que o sujeito ocupa na sociedade".

Em outras palavras, o discurso da anoréxica está relacionado com o lugar social que o sujeito ocupa numa determinada formação social e cultural. O lugar social compreende o espaço empírico: o convento, o circo, o blog e, mais do que isso, o consultório, a rua, a escola, a casa onde mora...

O lugar social, por sua vez, relaciona-se com o que, em $A D$, chamamos de lugar discursivo. No entanto, não há uma relação de equivalência, nem de linearidade entre lugar social e lugar discursivo. Nem sempre o lugar discursivo corresponde ao lugar social e vice-versa, por isso, não se pode falar em simples transposição de um para o outro. Não obstante, há o que se pode chamar de passagem do lugar social para o discursivo. Nessa teorização, a formação discursiva compreende um espaço discursivo, relativo a um lugar discursivo que, por sua vez, "[...] se relaciona tanto com a forma-sujeito quanto com as diferentes posiçõessujeito que operam no discurso a partir dele" (ibidem, p. 58).

De acordo com Grigoletto (ibidem, p. 54), o espaço do empírico é aquele em que o sujeito do discurso se inscreve quando de sua interpelação ideológica no interior de uma formação social. Na passagem para o espaço discursivo, o lugar que o sujeito ocupa numa determinada formação social e ideológica é afetado pelas relações de poder, que determinam o seu lugar discursivo, através do movimento da formasujeito e da própria formação discursiva com a qual o sujeito se identifica.

Nessa reflexão, observa-se que o lugar discursivo é determinado pelo lugar social, da mesma forma que este é também construído pela prática discursiva. Trata-se de uma constituição mútua, sendo possível pensar o lugar discursivo como uma categoria de análise que, segundo Grigoletto (ibidem, p. 56),

[...] é materializada na passagem do espaço empírico, onde se encontram os lugares sociais, para o espaço discursivo. Ou seja, o 
lugar discursivo estaria no entremeio do lugar social, da forma e da posição-sujeito.

Observemos, pelo esquema:

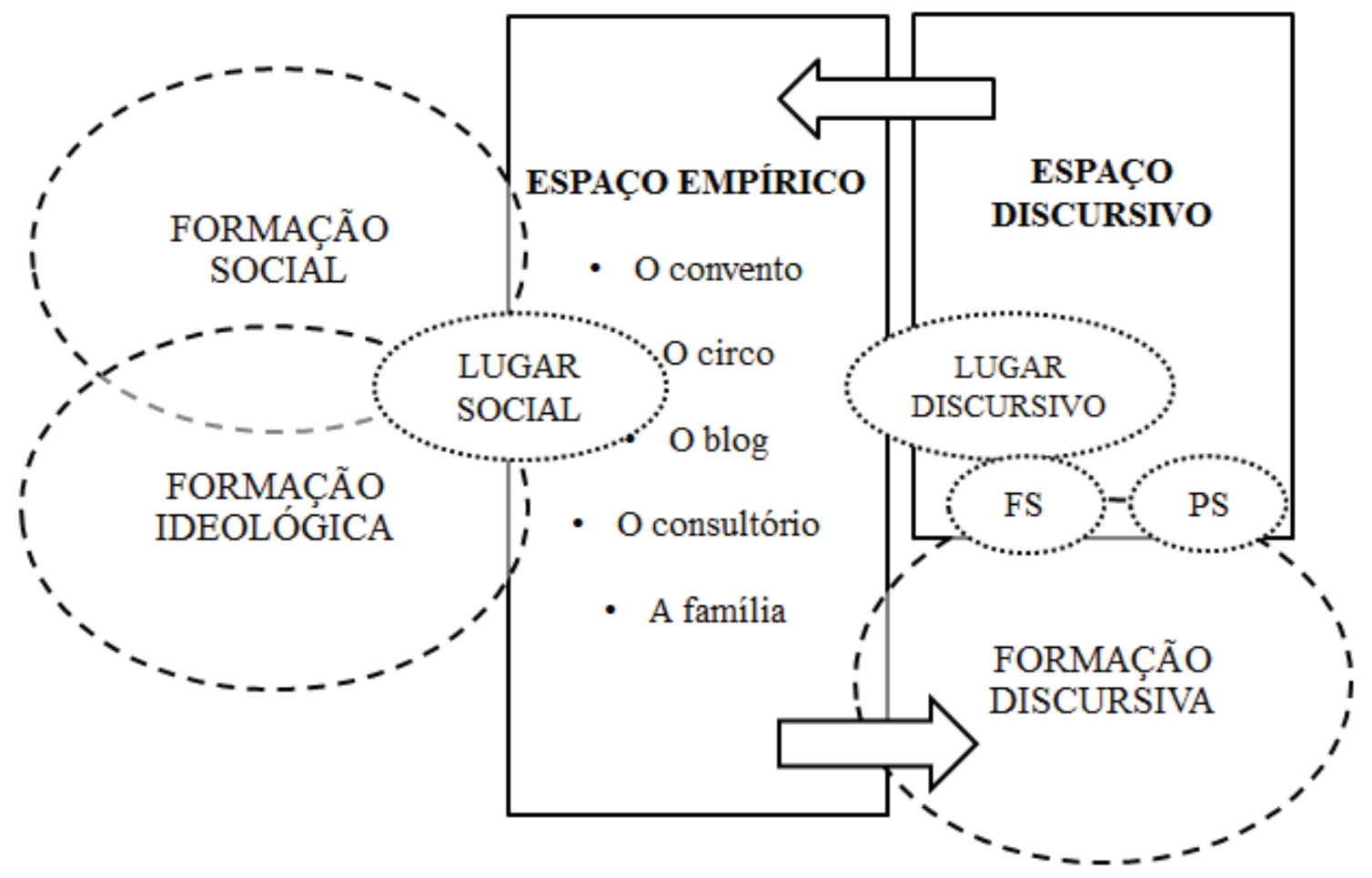

Esquema 2: Lugar discursivo

FS - Forma-sujeito

PS - Posição-sujeito

É nesse sentido que o discurso da anoréxica, na atualidade, abriga uma rede de memória que diz respeito à própria historicidade da anorexia: os lugares ocupados pelas anoréxicas ao longo do tempo. A formação a discursiva constitui-se pela porosidade, de modo que esses lugares sociais (o convento - sagrado; o circo - o profano), com certos deslocamentos, ressoam e são ressignificados, hoje em dia. $\mathrm{O}$ sagrado e o profano, discursivamente, coabitam um mesmo lugar discursivo, o da anoréxica, em diferentes lugares sociais, no blog, por exemplo.

\section{O não-lugar, ou lugar de entremeio}

De "Ana, a santa" à profanação dos espetáculos circenses, a anoréxica, na atualidade, ocupa distintos lugares sociais - o blog, o 
consultório, a família - que, no espaço discursivo, tornam-se lugares discursivos, pelos quais ficamos sabendo que pode ser tanto a "porca louca" quanto a "borboleta".

Com base em Grigoletto (2008) e Indursky (2013), podemos diferenciar, teoricamente, as noções de lugar social e lugar discursivo e ver que os lugares sociais (espaço empírico), ao se transformarem em lugares discursivos (espaço discursivo), retomam uma memória que confere historicidade ao objeto discursivo; possibilitam distintas tomadas de posição do sujeito; dão visibilidade a formas de subjetivação que, de outro modo, permaneceriam invisíveis no interior da formação social da qual fazem parte.

Podemos observar que essas tomadas de posição são, por vezes, paradoxais, na medida em que, a partir delas, não sabemos se o sujeito, da forma como se subjetiva numa formação social capitalista, do consumo, em rede e do espetáculo, nela se aliena ou dela busca se separar. Outrossim, essas distintas tomadas de posição do sujeito materializam formas de resistência (embora, algumas vezes, às avessas), pelo estatuto da equivocidade, que abriga, em seu interior, a contradição. Necessariamente, a contradição não produz o efeito de sentido de resistência. No entanto, é o que permite, não sem tensão, fazer com que o profano conviva com o sagrado; que público e privado se imbriquem na direção de um endereçamento; que a fragmentação se sobreponha à unidade imaginária.

A contradição afeta e constitui a tomada de posição do sujeito. Por conta disso, mesmo que tenhamos falado em distintos, e por isso mesmo, em singulares lugares sociais, que se transformam em diferentes, e também singulares lugares discursivos, pelo sujeito anoréxico, podemos visualizar uma outra configuração do lugar, o não-lugar, que não tem a ver com a negação do lugar, mas com o que poderíamos chamar de o lugar de entremeio. É o que podemos visualizar no esquema: 


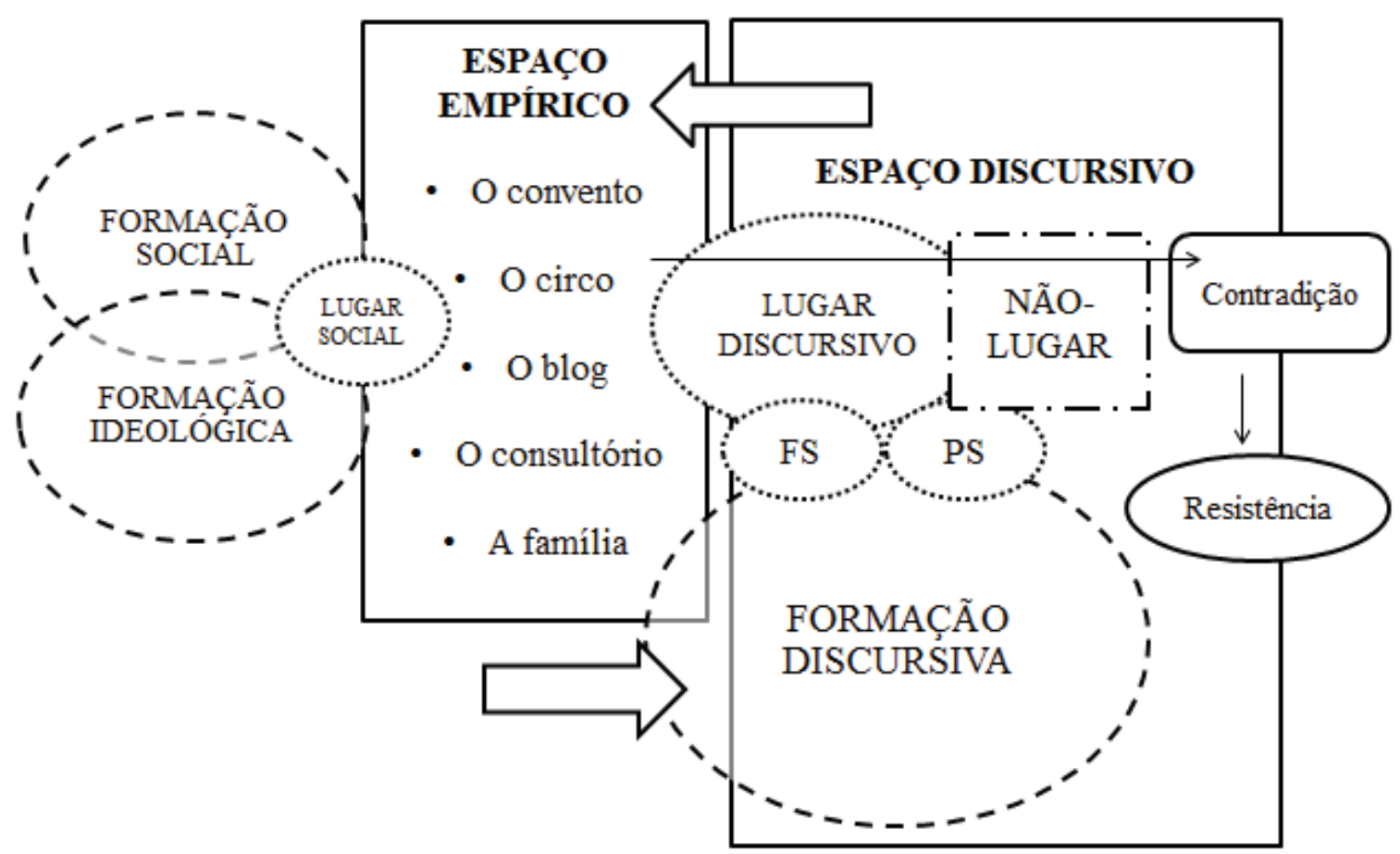

Esquema 3: $\bigcirc$ não-lugar

FS - Forma-sujeito

PS - Posição-sujeito

Quando falamos em não-lugar ${ }^{52}$, tomamos por referência a conceituação de dois autores, Augé (2012) e De Certeau (2014). No entanto, buscamos contrapô-las com a teorização de Castells (1999) acerca do "espaço de fluxos", constituído numa sociedade em rede. A partir das aproximações e distanciamentos entre as noções de não-lugar e de entremeio, esta elaborada pela $\mathrm{AD}$, buscamos, ao nosso modo, pensar no processo de subjetivação do sujeito na posição de anoréxica. Vejamos.

Para De Certeau (2014), o “espaço é um lugar praticado”. Em outras palavras, o sujeito, pelo trabalho simbólico, transforma o lugar em espaço a partir de sua ocupação, apropriação e vivência. Sem fazer a distinção entre espaço e lugar proposta por De Certeau, mas, também, sem negar suas contribuições, Augé (2012) trabalha com as noções de lugar antropológico e "não lugar". São noções que nos permitem pensar nas transformações que surgem de uma forma aparentemente natural, que ocorrem na vida cotidiana de cada um e que resultam do processo de globalização, refletindo-se no modo como nos relacionamos com o

${ }^{52}$ Em Augé (ibidem), a expressão é grafada "não lugar". Optamos pela grafia "nãolugar”, a fim de conceituar essa noção a partir da teoria do discurso. 
espaço, com o tempo e com os outros. A transformação das cidades, sob o enfoque de Augé, é exemplo de como o lugar antropológico, definido como um espaço identitário, relacional e histórico, passou a ser constituído como um "não lugar" no que o autor chama de sobremodernidade.

O "não lugar" é designado como duas realidades complementares, porém distintas. São espaços constituídos em relação a certos fins (transporte, trânsito, comércio, lazer) e a relação que os indivíduos mantêm com esses espaços. A partir daí, o "não lugar" constitui-se como o que fabrica o "homem médio", tendo em vista que esse espaço não cria nem identidade singular nem relação, mas sim solidão e similitude. A história é transformada em elemento do espetáculo, de modo que "os consumidores do espaço acham-se, assim, presos nas ressonâncias e nas imagens de uma espécie de cosmologia objetivamente universal, simultaneamente familiar e prestigiosa" (AUGÉ, 2012, p. 97). Trata-se de uma cosmologia que produz efeitos de reconhecimento, uma vez que nesse mundo de consumo, o indivíduo pode fazer parte porque é nele incessantemente interpelado.

Com base nisso, é possível dizer que a inquietação de Augé recai sobre a súbita e rápida transformação dos lugares em "não lugares" espaços de anonimato e solidão, nos quais o que prevalece é a liberdade do indivíduo em detrimento do sentido construído socialmente. Essa inquietação se aproxima e, ao mesmo tempo, se distancia da elaboração proposta por Castells (1999), uma vez que este, em seu percurso de investigação, defende que a organização do espaço é um elemento crucial para a compreensão da sociedade contemporânea. Contrapondo a maioria das teorias clássicas, que supõem o domínio do espaço pelo tempo, o autor propõe a hipótese de que é o espaço que organiza o tempo numa sociedade em rede.

Castells (1999) chama de "espaço de fluxos" essa nova lógica espacial que resulta da interação entre tecnologia, sociedade e espaço. Trata-se de um espaço constituído a partir de um conjunto de serviços avançados e que se materializa em uma organização em torno de centros de controle e comando. O "espaço de fluxos" (de capital, de informação, de tecnologia, de interação organizacional, de imagens, sons e símbolos) é exatamente o oposto do "espaço de lugares" (uma organização espacial historicamente enraizada). O lugar é um local cuja forma, função e significado são independentes dentro das fronteiras da contiguidade física. 
O "espaço de fluxos" é a lógica espacial que predomina numa sociedade em rede, visto que corresponde aos interesses de uma elite empresarial tecnocrática e financeira com exigências espaciais específicas. Essas exigências determinam a relação de apropriação e controle do espaço, constituindo comunidades simbólica e espacialmente segregadas. Dessa maneira, o "espaço de fluxos" não é apenas um espaço geográfico ligado às novas tecnologias de informação e à globalização; é também um espaço social de uma elite dirigente, ligado ao poder e à riqueza. Trata-se de um espaço de consumo, de circulação e de comunicação - um espaço global - marcado por um horizonte de espaço de fluxos a-histórico em rede, que acaba impondo a sua lógica nos lugares segmentados e espalhados, os quais se relacionam cada vez menos uns com os outros e tornam-se cada vez menos capazes de compartilhar códigos culturais comuns.

A partir daí, o "espaço de fluxos" torna-se um "não lugar", no qual as interações são espetacularizadas, mediadas por imagens, regidas pela lógica do consumo e notadamente efêmeras. Por outro lado, nesse mesmo movimento, vemos o lugar tornar-se espaço, na medida em que o sujeito dele se apropria, nele se inscreve e nele se (re)inventa. É nesse sentido que propomos que a noção de "não-lugar", por meio de um desdobramento, seja trabalhada não como a negação do lugar, mas como o lugar de entremeio. Mais do que isso, o lugar da contradição e da resistência.

Em AD, a noção de entremeio é trabalhada como forma de caracterizar a própria disciplina de interpretação fundada por Pêcheux, a partir da desterritorialização de três campos de saber - a linguística, a psicanálise e o marxismo. Enquanto disciplina de entremeio, a $\mathrm{AD}$ se constitui a partir das relações contraditórias entre as teorias, situando-se justamente nesse lugar em que é pensada a partir de espaços relacionais entre disciplinas. Com base em Robin, Ferreira (2003, p. 41) afirma que a $\mathrm{AD}$ não pode ser considerada "nem disciplina autônoma, nem disciplina auxiliar". Trata-se, antes, de tematizar o objeto discursivo como sendo um objeto-fronteira, "[...] que trabalha nos limites das grandes divisões disciplinares, sendo constituído de uma materialidade linguística e de uma materialidade histórica, simultaneamente" (ibidem).

A noção de entremeio tem a ver, na perspectiva discursiva, com noções como território e fronteira. Entretanto, trata-se de um lugar constituído pela contradição, visto que as fronteiras são porosas e o território é movediço. Pelo gesto de desterritorializar, à $\mathrm{AD}$ é conferida 
singularidade, da mesma forma que uma relação estranho-familiar é estabelecida com as teorias a partir das quais é forjada.

Isso posto, o não-lugar como lugar de entremeio poderia ser caracterizado como um lugar que se constitui pela contradição, pela porosidade de suas fronteiras e pela movência de seu território. Os limites que separam o dentro e o fora são opacos, assim como os efeitos de sentido nele e a partir dele produzidos não são transparentes. Um lugar em que esses limites (território e fronteira) se estabelecem a partir do jogo entre presença e ausência.

O não-lugar de que falamos, portanto, não pode ser confundido com as oposições entre espaço e lugar (DE CERTEAU, 2014), lugar antropológico e "não lugar" (AUGÉ, 2012) e espaço de lugares e espaço de fluxos (CASTELLS, 1999). Não se trata, aqui, de opor a noção de nãolugar à de lugar discursivo, ou de lugar social. A categoria de não-lugar, do modo como propomos, pode estar vinculada tanto ao lugar social (espaço empírico), quanto ao lugar discursivo (espaço discursivo). No entanto, trata-se de uma categoria que se situa no entremeio.

Para melhor visualizarmos a questão, vejamos o quadro abaixo:

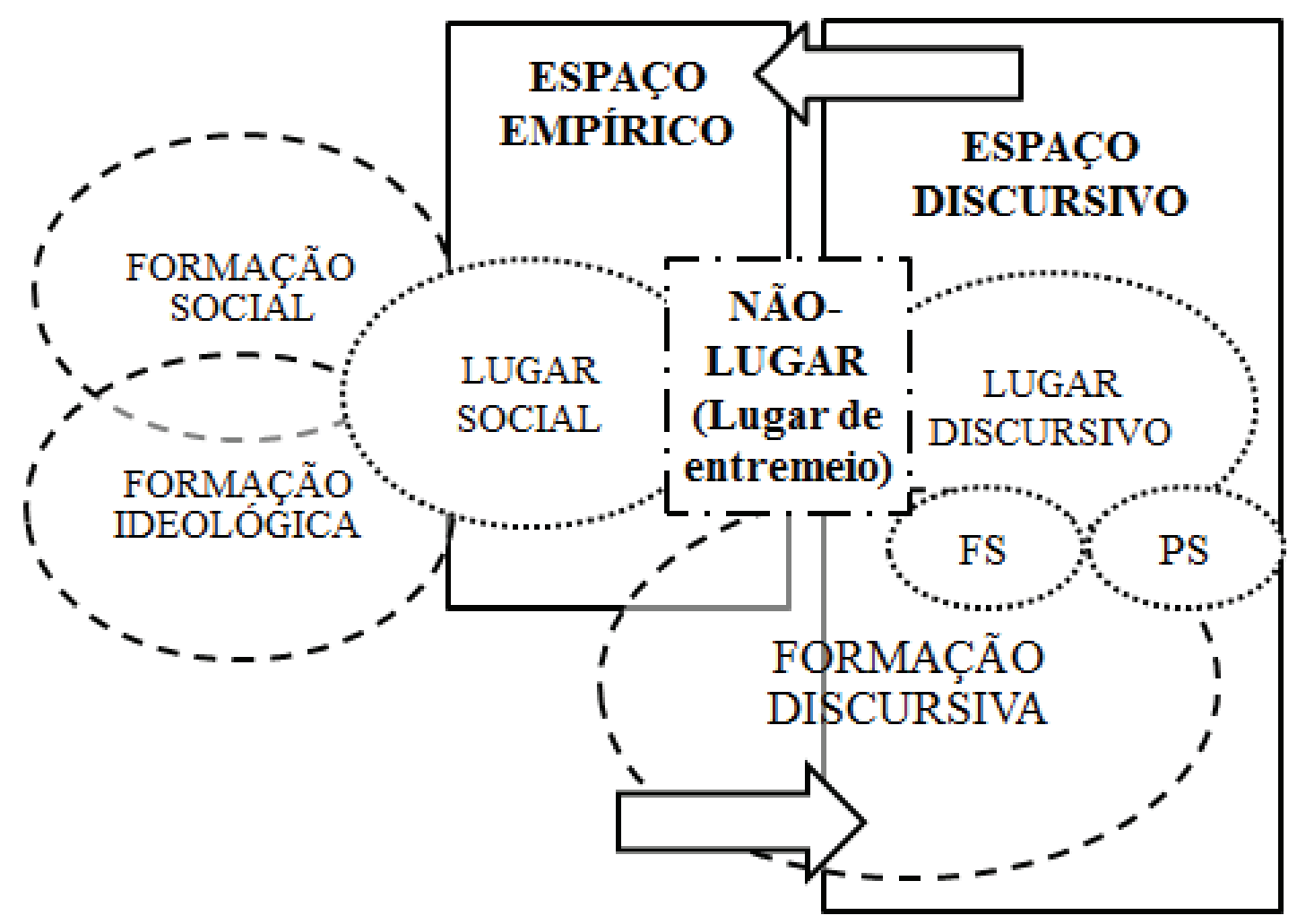

Esquema 4: Não-lugar - categoria de entremeio

FS - Forma-sujeito

PS - Posição-sujeito 
E voltemos ao nosso objeto, as anoréxicas e os lugares pelos quais circulam e se subjetivam (o blog, o consultório, a família, nos quais ressoam a memória do convento e do espetáculo circense). Nesses lugares sociais, que passam a ser discursivos pela relação que se estabelece entre a forma e a posição-sujeito no interior de uma determinada formação discursiva, o sujeito assume distintas posições, as quais dialogam, tensamente, com outras FDs. Nessas posições, os efeitos de sentidos são contraditórios, ambivalentes, paradoxais.

Não há processo de identificação plenamente bem sucedido, uma vez que as fronteiras que delimitam o território de uma FD são porosas. As fronteiras são presentes e ausentes ao mesmo tempo, da mesma forma que a inscrição do sujeito no interior dessa FD não é unívoca nem transparente. Os outros discursos estão presentes e ausentes, de forma que há tanto identificação quanto contra-identificação do sujeito a esses saberes. O sujeito não está nem plenamente dentro nem de todo fora. Situa-se no entremeio, no não-lugar.

Daí a relação ser da ordem do estranho-familiar. Nesses lugares discursivos, o sujeito, na posição de anoréxica, sente-se, ao mesmo tempo, estranho e familiar com relação ao outro que lhe constitui. O outro é para ele ora familiar, ora um estranho - até mesmo uma ameaça. Há uma busca por reconhecimento, pelo endereçamento, pela conformação de uma identidade imaginária e nesse processo o outro se torna familiar. No entanto, o outro também se torna uma ameaça: a banha, a gordura; por vezes, a família, por vezes o médico, o hospital; por vezes a própria anorexia. Esta, seja como doença, seja como estilo de vida, torna-se um outro, do qual é preciso se livrar. O sujeito, nessa posição, torna-se um estranho para si mesmo, uma vez que "Sou onde não penso", "Quando como não penso em nada" ${ }^{53}$.

A partir daí podemos dizer que o próprio corpo da anoréxica pode ser um lugar de entremeio, um não-lugar. Isso porque, no interior do discurso médico, a anoréxica é comumente chamada como "borderline". Borderline é uma expressão utilizada para indicar os chamados "casoslimite", nos quais as fronteiras que demarcam, no corpo, o dentro e o

53 É possível, aqui, estabelecer uma relação com a Psicanálise, em especial a lacaniana, tendo em vista a concepção de sujeito do inconsciente. Esta se distancia do "cogito ergo sum" de Descartes - teoria segundo a qual o sujeito seria dotado de racionalidade. 
fora, estão ausentes. $\mathrm{O}$ interesse por essa novidade nosográfica, de acordo com Fernandes (2012, p. 173),

[...] reside justamente na noção de limite, mais precisamente na noção de fronteira, o que, aliás, essas patologias parecem evocar a todo momento. Fronteira entre dentro e fora, entre eu e outro, entre realidade e fantasia, entre a representação e o irrepresentável.

$\mathrm{Na}$ anorexia, há uma distorção da imagem corporal: o eu não se reconhece quando se olha no espelho. Há, portanto, uma perturbação na percepção do corpo, suas sensações, sua forma, suas dimensões, seu contorno que significa uma dificuldade de discriminação entre dentro e fora. Nas palavras de Fernandes (ibidem, p. 172), "tudo se passa como se o corpo próprio não exercesse aí uma de suas funções que é colocar os limites entre o dentro e o fora".

Para além disso, a anorexia questiona as próprias definições que lhe são conferidas. Como doença, ela mesma possui limites opacos. É considerada, por vezes, como fronteira entre neurose, psicose, perversão, melancolia e hipocondria. De modo que, para Fernandes (ibidem, p. 173), as anorexias e bulimias contribuem "[...] para um questionamento das fronteiras das categorias nosográficas em si, assim como dos diversos campos teóricos e metodológicos que as investigam”.

Podemos dizer, a partir daí, que tanto a anorexia, como doença, quanto a anoréxica, na relação que estabelece com o próprio corpo e com os lugares pelos quais circula e se inscreve, são desterritorializadas. Não possuem lugar definido e suas fronteiras também não são plenamente demarcadas. $O$ que não significa não ter lugar, não ter fronteira. Pelo contrário, a anorexia e a anoréxica imprimem um gesto de desterritorialização, que se desdobra em singularidade e resistência.

Lembremos que, para De Certeau (2014), o não-lugar tem a ver justamente com a utopia e com a resistência. Utopia é uma palavra inventada por Thomas More, no século XVI. Do grego, ela é formada por "OU", que significa "não" e "TOPOS", "lugar". Literalmente seria "não lugar" ou "lugar nenhum" - a negação do lugar. Entretanto, os utopistas a usavam para representar um lugar onde tudo pudesse funcionar perfeitamente. 
A utopia, portanto, não equivale à negação do lugar, nem ao lugar do plenamente perfeito. Ao abordar as culturas populares, De Certeau (2014) trabalha com dois níveis estratificados do espaço: o espaço utópico e sua relação tensa e contraditória com o espaço polemológico. Este é considerado como um espaço socioeconômico, organizado por uma luta imemorial entre poderosos e pobres, que se apresenta como um campo de perpétuas vitórias dos ricos e da polícia, mas também como o reinado da mentira, onde os fortes ganham e as palavras enganam. O espaço utópico, por outro lado, escondido sob o manto da língua falada, afirma um possível diante do espaço polemológico.

Para este autor (ibidem, p. 74), na luta entre poderosos e pobres, estes "oferecem ao possível um lugar inexpugnável, por ser um não lugar, uma utopia”. Dito de outro modo, a opacidade da cultura popular cria uma maneira de driblar as imposições do espaço polemológico mesmo no interior desse espaço. É uma maneira singular de criar uma outra lei, no interior da lei imposta, de dizer "[... ] uma verdade não redutível às crenças particulares que lhe servem de metáforas ou de símbolos”. E essa maneira de utilizar sistemas impostos acaba constituindo-se como resistência à lei histórica de um estado de fato e a suas legitimações dogmáticas.

O não-lugar, do modo como articulamos, é, também, uma forma de resistência, por permitir que as singularidades (e os equívocos) venham à tona mesmo no interior de um sistema homogeneizante, numa sociedade em rede, do espetáculo, em suma, capitalista. Ocupar o nãolugar significa, nesse sentido, resistir e resistir é transgredir a norma, criando uma outra norma.

O corpo da anoréxica estabelece com a noção de fronteira uma relação de presença-ausência. O próprio corpo materializa o não-lugar. Mais do que isso, o sujeito, na posição de anoréxica, ao dizer "Sou a vergonha em pessoa. Não consigo me imaginar magra o suficiente para me deixar feliz", materializa sua posição de entremeio, no não-lugar. Um lugar do paradoxo, da contradição, no interior da formação social capitalista, da sociedade em rede, da sociedade do espetáculo. A anoréxica é uma transgressora em relação às normas; cria outras normas. Resiste. Nos expõe ao paradoxo, à contradição.

\section{Para fechar, se possível}

Se pensarmos no fechamento de um círculo, por exemplo, veremos que o ponto final encontra o ponto inicial. Assim se processa o 
nosso efeito de fechamento. $\mathrm{O}$ que, de maneira nenhuma, significa dar voltas sobre um mesmo objeto sem sair do lugar.

Se é possível produzir um efeito de fechamento de nosso texto, precisamos voltar ao início, e lembrar nosso leitor que, ao visualizarmos o corpo das anoréxicas, considerado como doente pela medicina, sob a lente da $\mathrm{AD}$, pode se transformar em lugar de entremeio, não-lugar, ou lugar de resistência. De doente, pelo modo como se subjetiva ao tomar lugar numa sociedade em rede e do espetáculo, o corpo da anoréxica passa a ser lugar da contradição, lugar em que o óbvio se estilhaça. Ou seja, numa sociedade em rede e do espetáculo, se o que vale é a imagem, a anoréxica nos dá a ver uma imagem que, talvez, para nós, é insuportável: a da própria morte. Numa sociedade em rede e do espetáculo, esta imagem pode ser uma, apenas uma das tantas formas possíveis de resistência. Uma forma contraditória e paradoxal de resistência - quando o sujeito "prefere" morrer de inanição a ser salvo. Mas, ainda assim, uma resistência: não se enquadrar no logicamente estabilizado. Habitar o nãolugar é justamente dar forma material à contradição. Em outras palavras, encontrar uma forma de resistir, no interior de uma formação social que se alegra com as formas logicamente estabilizadas.

\section{REFERÊNCIAS}

AUGÉ, M. Não lugares: introdução a uma antropologia da supermodernidade. Trad. Maria Lúcia Pereira. 9. ed. Campinas, São Paulo: Papirus, 2012.

CASTELLS, M. A sociedade em rede. Vol. I. Trad. Roneide Venancio Majer. 8. ed. São Paulo: Paz e Terra, 1999.

DEBORD, G. A sociedade do espetáculo. Marxists, 2003. Disponível em: <https://www.marxists.org/portugues/debord/1967/11/sociedad e.pdf> Acesso em: 02 set. 2016.

DE CERTEAU, M. A invenção do cotidiano: 1. Artes de fazer. Trad. Ephraim Ferreira Alves. 22. ed. Petrópolis, Rio de Janeiro: Vozes, 2014.

FERNANDES, M. H. Transtornos alimentares: anorexia e bulimia. São Paulo: casa do Psicólogo, 2012.

FERREIRA, M. C. L. O quadro atual da Análise de Discurso no Brasil. In: Espaços da Linguagem. PPGL - UFSM. Letras n. 27, jul/dez 2003. 
GRIGOLETTO, E. Do lugar discursivo à posição-sujeito: os movimentos do sujeito-jornalista no discurso de divulgação científica. In: MITTMANN, S.; GRIGOlETTO, E.; CAZARIN, E. A. (orgs). Práticas discursivas e identitárias: sujeito e língua. Porto Alegre: Nova Prova, 2008.

INDURSKY, F. O ideológico e o político no discurso do/sobre o MST. In: INDURSKY, F.; FERREIRA, M. C. L.; MITTMANN, S. O acontecimento do discurso no Brasil. São Paulo: Mercado de Letras, 2013.

PÊCHEUX, M.(1969) A análise automática do discurso. Trad. Eni Pulcinelli Orlandi. In: GADET, F. e HAK, T. (Orgs.) Por uma análise automática do discurso: uma introdução à obra de Michel Pêcheux. Campinas, São Paulo: Editora da Unicamp, 1993.

Recebido em: 09/10/2018

Aceito em: 30/10/2018 